\title{
Polyuria in a patient on chronic lithium therapy: a case report and literature review
}

\author{
C J Subasinghe ${ }^{1}$, L D Ranasinghe ${ }^{1}$, D U S Bulugahapitiya ${ }^{1}$
}

Sri Lanka Journal of Diabetes, Endocrinology and Metabolism 2015; 5: 34-37

\begin{abstract}
Lithium ( $\mathrm{Li}$ ) has been associated with several forms of renal injury, the most prevalent being impaired urinary concentrating ability, which is reported in individuals on chronic lithium therapy. Lithium is the most common drug implicated in acquired nephrogenic diabetes insipidus (NDI). Prevalence of NDI correlates with the Li dose and the duration of therapy. Here we report an elderly male, presented with hypotonic polyuria while being on prolonged Li therapy for more than 20 years for bipolar affective disorder. Further evaluation confirmed the diagnosis of Li induced NDI as the aetiology for polyuria which responded to Li dose reduction and Thiazide therapy. Proper evaluation of a patient presenting with hypotonic polyuria with water deprivation followed by a desmopressin challenge is necessary before diagnosis, as therapy differs according to the type of the disease. Usually the concentration defect is at least partially reversible with drug discontinuation. Amiloride minimizes lithium accumulation in collecting tubule cells and is recommended for those patients, in whom Lithium therapy cannot be discontinued.
\end{abstract}

\section{Introduction}

Lithium is recommended as the first-line therapy for treatment of bipolar disorder for more than 50 years due to excellent therapeutic efficacy despite various adverse effects. Polyuria has generally been defined as urine output exceeding $3 \mathrm{~L} /$ day in adults and $2 \mathrm{~L} / \mathrm{m}^{2}$ in children. It must be differentiated from the more common complaints of frequency or nocturia, which are not associated with an increase in the total urine output. Diabetes insipidus (DI) belongs to the spectrum of polyuric and polydipsic diseases, a group of hereditary or acquired disorders mainly associated with an inadequate Arginine Vasopressin (AVP) secretion or renal response to AVP, which clinically results in hypotonic polyuria and a compensatory or underlying polydipsia. Lithium is the commonest acquired cause of nephrogenic diabetes insipidus, which is caused by impaired renal concentrating ability due to various mechanisms. Polyuria in a patient who is on Lithium could be due to various causes including NDI, cranial DI, primary polydipsia and tubulointerstitial nephritis. Furthermore, long term Li therapy leads to hyperparathyroidism causing hypercalcaemia and polyuria. Therefore, polyuria in a patient who is on $\mathrm{Li}$ requires a proper diagnostic evaluation. Elderly psychiatric patients are more prone to develop complications of polyuria, such as dehydration, electrolyte imbalance, neurological problems irrespective of the underlying aetiology. Most importantly all these factors predisposes these patients to Li toxicity, and therefore proper evaluation and prompt correction should be done.

\section{Case report}

A 66 years old man with bipolar affective disorder who had been on $\mathrm{LiCO}_{3}$ (current dose $-1 \mathrm{~g}$ nocte ) for 20 years presented with nocturia, polyuria and excessive thirst for 4 months duration. There was no past history of diabetes mellitus and he did not have other symptoms of hypercalcaemia. He also complained of a bilateral hand tremor, but not other symptoms suggestive of Li toxicity.

On examination, he was dehydrated and had coarse tremors of hands. Rest of the examination was unremarkable. Investigations revealed slightly elevated serum Li levels (1.22 mEq/L \{therapeutic range; 0.6-1.2, toxic $>1.5\})$. Fasting blood glucose and serum calcium were normal. Renal function test showed mild elevation of serum creatinine $(1.41 \mu \mathrm{mol} / \mathrm{l})$. Serum electrolytes revealed hypernatraemia (Na- $148 \mathrm{mmol} / \mathrm{l}$ ) with normokalemia. Based on the history, Li induced NDI was suspected and further evaluation was done. His serum osmolality was high (304 $\mathrm{mOsm} / \mathrm{kg} \mathrm{H} 2 \mathrm{O}$ ) with low urinary osmolality (192 mOsm $/ \mathrm{kg}$ $\mathrm{H} 2 \mathrm{O}$ ). A water deprivation test (Table 1) was done to confirm the diagnosis of Li induced nephrogenic DI.

With water deprivation, polyuria persisted and serum osmolality increased without appropriate concentration of urine, suggesting DI. Urine osmolality did not improve with Vasopressin, confirming complete nephrogenic DI in our patient. Li dose was reduced after psychiatrist opinion. Since Amiloride was not available, Hydrochlorothiazide $25 \mathrm{mg}$ was started with close monitoring of serum

${ }^{1}$ Department of diabetes and endocrinology, Colombo south teaching hospital, Sri Lanka. 
Table 1. Water deprivation test

\begin{tabular}{llllll}
\hline Time & Weight $(\mathrm{kg})$ & Urine vol. $(\mathrm{mL})$ & S. $\mathrm{Na}+(\mathrm{mmoL} / \mathrm{L})$ & $\begin{array}{l}\text { S. Osmolality } \\
\left(\mathrm{mOsm} / \mathrm{kgH}_{2} \mathrm{O}\right)\end{array}$ & $\begin{array}{l}\text { Urine osmolality } \\
\left(\mathrm{mOsm} / \mathrm{kgH}_{2} \mathrm{O}\right)\end{array}$ \\
\hline $0800 \mathrm{~h}$ & 65.55 & $350 \mathrm{ml}$ & 143 & 303 & 77 \\
$0900 \mathrm{~h}$ & 65.4 & 360 & 144 & & 81 \\
$1000 \mathrm{~h}$ & 65.55 & 360 & 143 & 307 & 89 \\
\multicolumn{1}{l}{$\begin{array}{l}\text { IM Vasopressin } 5 \mathrm{U} \text { at } 1200 \mathrm{~h} \\
1300 \mathrm{~h}\end{array}$} & 65.5 & 300 & 147 & & \\
$1400 \mathrm{~h}$ & 65.1 & 250 & 147 & 384 & 168 \\
\hline
\end{tabular}

electrolytes. With this treatment there was a remarkable improvement in symptoms with reduction of urinary frequency, thirst and resolution of nocturia.

\section{Discussion and literature review}

Polyuria is defined as a urine output of more than $3 \mathrm{~L} /$ day in adults. With the exclusion of glucose induced osmotic diuresis, which occurs in uncontrolled diabetes mellitus, other three major causes of hypotonic polyuria (urine osmolality usually $<250 \mathrm{mosmol} / \mathrm{kg}$ ) are primary polydipsia, central DI and nephrogenic DI. Nephrogenic diabetes insipidus (NDI) results from renal resistance to antidiuretic action of Arginine Vasopressin (AVP), which clinically results in hypotonic polyuria and a compensatory polydipsia. Acquired form of NDI is much more common than congenital NDI, while chronic Lithium use and hypercalcemia being the most common causes of a defect severe enough to produce polyuria $(1,2,3)$.

Normally water permeability of principal cells in collecting ducts $(\mathrm{CD})$ is regulated by anti diuretic hormone $(\mathrm{ADH})$. Aquaporin $2\left(\mathrm{AQP}_{2}\right)$ water channels, which normally reside in endosomes of principal cells, move to and fuse with luminal membrane under influence of $\mathrm{ADH}$, allowing water to be reabsorbed down the favourable concentration gradient. On average, Li reduces urinary concentrating ability by $15 \%$ of normal maximum by different mechanisms (2). Even at therapeutic concentration, lithium may interfere with intracellular Vasopressin signaling systems mainly including CAMP system, leading to decreased renal AQP2 receptor expression $(1,4,5,6)$. In addition, $\mathrm{Li}$ also reduces protein abundances of urea transporters (UTA1, UTB), thereby reducing medullary interstitial osmolality, which causes impaired countercurrent exchange and renal concentrating ability (6). Lithium accumulates in the distal tubular cells of the kidneys at concentrations 10-20 times higher than in serum. Epithelial sodium channels $(\mathrm{ENaC})$ play a crucial role as the entry route for intracellular $\mathrm{Li}$ accumulation (7). In most cases, there is a correlation between impaired concentration ability and duration of $\mathrm{Li}$ and total $\mathrm{Li}$ dose (8). In one study, patients who had been on the drug for more than 18 years invariably had an irreversible defect (3). Between $20-70 \%$ of patients taking Li have a moderate increase in urine volume $(>2.5 \mathrm{~L} / \mathrm{d}$ ) while up to $12 \%$ have frank DI characterized by polyuria ( $>3 \mathrm{~L} / \mathrm{d})$, hypernatraemia, and neurological symptoms $(6,9)$. Our patient had been on variable doses of Li for about 20 years when he presented with symptoms.

It should not be assumed that polyuria in a patient taking Li is always due to NDI. Both cranial DI and primary polydipsia have also been described in patients treated with $\mathrm{Li}$. Therefore once hypotonic polyuria is confirmed, these patients should undergo proper diagnostic evaluation of differential diagnosis. Current diagnostic test concepts of DI date back to animal studies from Gilman and Goodman in the 1930s, which first demonstrated that osmotic stimulation by dehydration induces an antidiuretic urinary response that is not observed in hypophysectomized dogs (10). A first standardized test protocol with detailed diagnostic test criteria was proposed by Miller et al. in 1970 after the evaluation of 36 patients with different disorders of polyuria and polydipsia syndrome (11). For the time being, we consider water deprivation followed by a desmopressin challenge as the most plausible test standard to assess the adequacy of AVP function (Figure 1). However, no agreement exists regarding the best test for diagnosis and most commonly followed protocols lack diagnostic accuracy (12).

The water restriction test in adults is continued until the maximal urinary concentration achieved, indicated by either the urine osmolality reaching a clearly normal value, the urine osmolality being stable on two or three successive hourly measurements despite a rising plasma osmolality, the plasma osmolality exceeding 295 to 300 mosmol $/ \mathrm{kg}$ or the plasma sodium being $145 \mathrm{meq} / \mathrm{L}$ or higher. Our patient failed to increase urine osmolality in response to water deprivation and to stimulation with Vasopressin, concluding the diagnosis of complete NDI. 
Figure 1. Diagnostic approach to hypotonic polyuria (12)

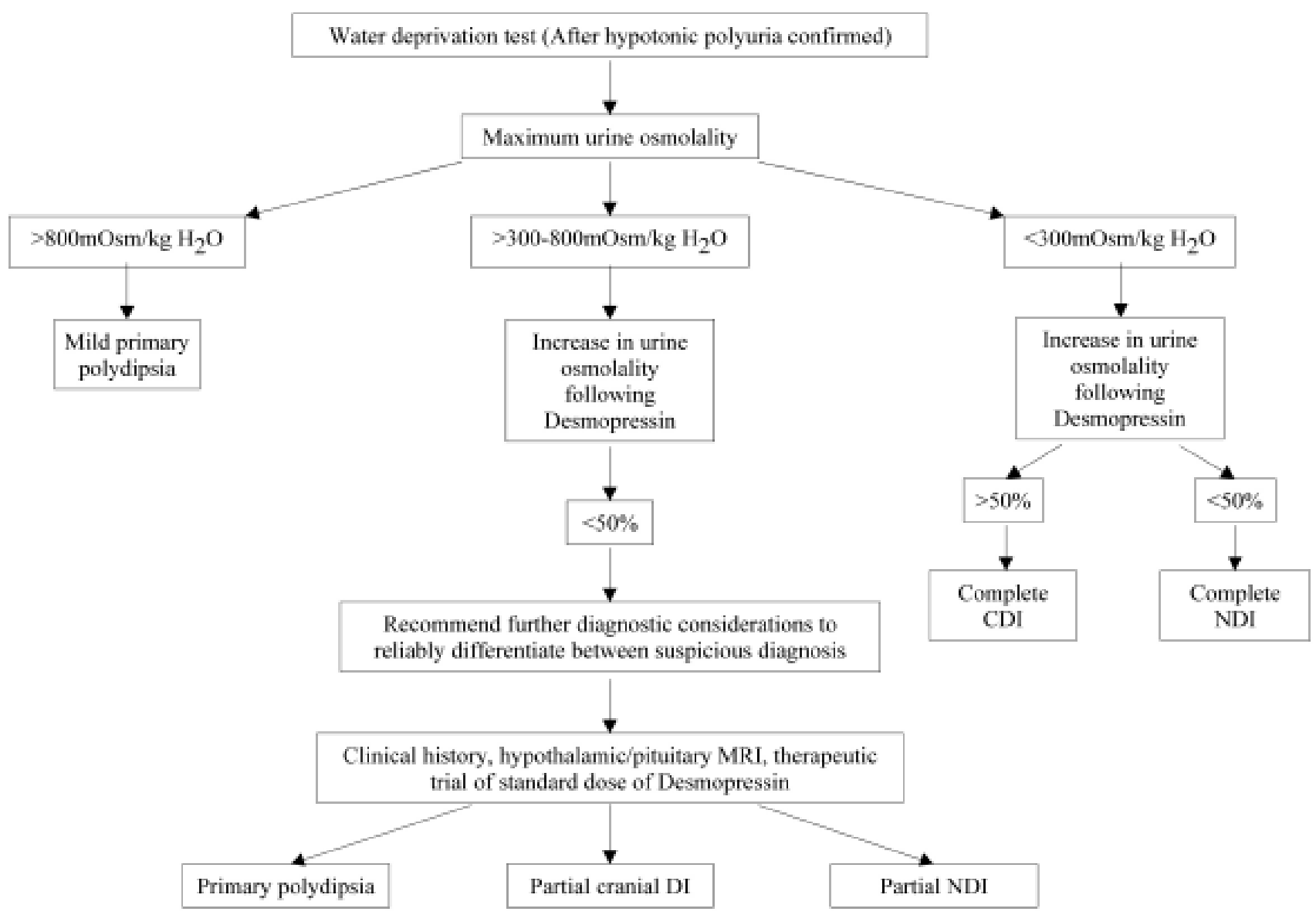

In diagnostically indeterminate cases, measurement of plasma AVP levels with a validated sensitive assay would be helpful. Emerging data on copeptin ( $\mathrm{C}$ terminal proAVP) measurement in response to an osmotic stimulus suggest that this surrogate provides a novel and more robust test concept than currently available testing methods (12).

Lithium induced concentrating defect is usually at least partially reversible, though it can be permanent after prolonged therapy. A case of persistent NDI has been reported 8 years after discontinuation of therapy (13). Therefore, Li therapy should be discontinued if possible, once $\mathrm{Li}$ induced DI is diagnosed. For those patients, in whom Li therapy is absolutely necessary, concomitant use of Amiloride is a better option $(7,14)$. Amiloride, in addition to its natriuretic action, it also reduces entry of Lithium into the distal tubule by inhibiting $\mathrm{ENaC}$ channels. It is likely to be effective in mild to moderate cases, but experience with Amiloride in severe cases is disappointing (9).
Other therapeutic options to manage polyuria are similar to those in other causes of NDI. Thiazide diuretics diminish distal water delivery and upregulate $\mathrm{AQP}_{2}$ receptors causing paradoxical effect of reducing polyuria while being a diuretic (15). Our patient's polyuria responded well to thiazide therapy. NSAIDs inhibit prostaglandin synthesis and thereby minimize the ADH inhibition by prostaglandins, creating a therapeutic place in NDI. Since most patients are partially resistant to $\mathrm{ADH}$, it is also possible that attaining supraphysiological levels of ADH will attenuate polyuria.

\section{Conclusion}

A psychiatric patient presenting with polyuric polydipsic syndrome, should be evaluated for possible $\mathrm{Li}$ induced diabetes insipidus, while excluding other possible causes such as primary polydipsia and cranial DI. Lithium is a very potent medication, which has proven renal toxicity on long term therapy with possible permanent damage 
with time. More validated test protocols will improve the diagnostic accuracy of diabetes insipidus and thereby treatment success in the future. Understanding the aetiology and pathophysiological basis of the underlying disease in depth to the molecular level would be of importance in selecting therapeutic options.

\section{References}

1. Trepiccione F, Christensen BM. Lithium-induced nephrogenic diabetes insipidus: new clinical and experimental findings. J Nephrol 2010; 23 Suppl 16: S43.

2. McKnight RF, Adida M, Budge $\mathrm{K}$, et al. Lithium toxicity profile: a systematic review and meta-analysis. Lancet 2012; 379: 721.

3. Bendz H, Aurell M. Drug-induced diabetes insipidus: incidence, prevention and management. Drug Saf 1999; 21: 449-56.

4. Cogan E, Svoboda M, Abramow M. Mechanisms of lithium vasopressin interaction in rabbit cortical collecting tubule. Am J Physiol 1987; 252: F1080-F1087.

5. Goldberg H, Clayman P, Skorecki K. Mechanism of Li inhibition of vasopressin-sensitive adenylate cyclase in cultured renal epithelial cells. Am J Physiol 1988; 255: F995F1002.

6. Marples D, Christensen S, Christensen EI, Ottosen PD, Nielsen S. Lithium-induced downregulation of aquaporin-2 water channel expression in rat kidney medulla. J Clin Invest 1995; 95: 1838-45.
7. Christensen BM, Zuber AM, Loffing J, et al. Lithium Absorption Promotes Nephrogenic Diabetes Insipidus. $J$ Am Soc Nephrol 2011; 22(2): 253-61.

8. Boton R, Gaviria M, Batlle DC. Prevalence, pathogenesis, an treatment of renal dysfunction associated with chronic lithium therapy. Am J Kidney Dis 1987; 10(5): 329-45.

9. Christensen BM, Kim YH, Kwon TH, Nielsen S. Lithium treatment induces a marked proliferation of primarily principal cells in rat kidney inner medullary collecting duct. Am J Physiol Renal Physiol 2006; 291: F39.

10. Gilman A, Goodman LS. The secretion of an antidiuretic hypophyseal hormone in response to the need for renal water conservation. Science 1936; 84: 24-5.

11. Miller M, Dalakos T, Moses AM, Fellerman H, Streeten D $\mathrm{H}$. Recognition of partial defects in antidiuretic hormone secretion. Ann Intern Med 1970; 73: 721-9.

12. Fenske W, Allolio B. Current State and Future Perspectives in the diagnosis of Diabetes Insipidus: A Clinical Review. $J$ Clin Endocrinol Metab 2012; 97(10): 3426-37.

13. Stone KA. Lithium-induced nephrogenic diabetes insipidus. J Am Board Fam Pract 1999; 12(1): 43-7.

14. Batlle DC, von Riotte A, Gaviria BS, et al. Amelioration of Poyuria by Amiloride in Patients Receiving Long-Term Lithium Therapy. $N$ Engl J Med 1985; 312: 408-14.

15. Magaldi A. New insights into the paradoxical effect of thiazides in diabetes insipidus therapy. Nephrol Dial Transplant 2000; 15: 1903-5. 